\title{
Effect of reduced fertilizer nitrogen application rates on yield and nitrogen recovery of sugar beet and potatoes
}

\author{
J. J. NEETESON \\ Institute for Soil Fertility, P.O. Box 30003, NL 9750 RA Haren, Netherlands
}

Received 16 March 1989; accepted 11 April 1989

\begin{abstract}
It was investigated how far fertilizer nitrogen application can be reduced before serious yield deficits occur, and to what extent the reductions result in higher recoveries of fertilizer nitrogen. For this purpose, $90,75,50$ and $0 \%$ of the fertilizer nitrogen rates recommended according to the current method were retrospectively applied to 150 sugar beet and 98 potato trials conducted earlier. When it is assumed that the chance of yield deficits larger than $5 \%$ is not allowed to exceed $5 \%$, the currently recommended fertilizer nitrogen application rate for sugar beet cannot be lowered, but the rate for potatoes can be reduced by about $25 \%$. The average yield deficit will then be about $1.5 \%$, and the recovery of fertilizer nitrogen by the potato tubers will be about $40 \%$. The effect of a change in the ratio of the cost of fertilizer nitrogen to the price of produce on the economically optimum application rate of fertilizer nitrogen was also investigated; it was determined on the basis of the average response curves of the 150 sugar beet and 98 potato trials. A change in the ratio of the cost of fertilizer nitrogen to the price of produce had a much smaller effect on the optimum application rate of fertilizer nitrogen for sugar beet than on that for potatoes. A fivefold increase in the ratio decreased the optimum for sugar beet by only $20 \%$, for potatoes by $50 \%$. However, it also considerably decreased farm income. The decrease was more than Dfl. 400 per ha for sugar beet and more than Dfl. 800 per ha for potatoes.
\end{abstract}

Keywords: crop yield, fertilizer nitrogen recovery, potatoes, price ratio, sugar beet

\section{Introduction}

The performance of various methods used to make nitrogen fertilizer recommendations for sugar beet and potatoes have recently been evaluated (Neeteson, 1989). The methods consisted of (1) applying a fixed rate in all situations, (2) the current Dutch method, which takes only the amount of soil mineral nitrogen present in the soil in early spring into account, and (3) a refinement of the current method, which also takes soil type and recent applications of organic manures into account. It was shown that the methods differed in the recommended rate of fertilizer nitrogen, the current method recommending the lowest rates. The three methods were not significantly different with respect to yields obtained and recovery of fertilizer nitro- 


\section{J. J. NEETESON}

gen. Despite differences in fertilizer nitrogen rates the yields were similar due to the presence of a long, flat segment in the response curves of sugar beet and potatoes.

In this paper it is investigated how far rates of fertilizer nitrogen application can be lowered before serious reductions in yield occur, and to what extent the reductions result in higher recoveries of fertilizer nitrogen. For this purpose, 90, 75, 50 and $0 \%$ of the fertilizer nitrogen rates recommended according to the current method were retrospectively applied to 150 sugar beet and 98 potato trials conducted earlier (Neeteson \& Zwetsloot, 1989). The yields and recoveries of fertilizer nitrogen were determined from the response curves obtained in the trials.

Since the present recommendations are based on a fixed ratio $P$ of the cost of $1 \mathrm{~kg}$ fertilizer nitrogen to the price of 1 tonne produce, viz. 0.01 for sugar beet and 0.006 for potatoes (Neeteson, 1989), the recommendations should be adjusted if a change in the value of $P$ would occur. It is quite possible that the value of $P$ will increase in the future when the current low prices of fertilizer nitrogen rise, not only due to higher energy costs, but possibly also due to a levy imposed on fertilizers (Williams, 1988). Therefore, in the present paper the effect of any change in the value of $P$ on the economically optimum application rate of fertilizer nitrogen was evaluated using the average response curves of the 150 sugar beet and 98 potato trials.

\section{Materials and methods}

Four reduced rates of fertilizer nitrogen recommended with the current advisory method $(90,75,50$, and $0 \%)$ were retrospectively applied in 150 sugar beet and 98 potato trials.

The current advisory method for nitrogen fertilization is based on the amount of mineral nitrogen present in the soil in early spring (Anon., 1986). The recommendations used in this paper (Table 1 ) were adapted from the recommendations given in Anon. (1986) in such a way that the ratio $\mathrm{P}$ of the cost of $1 \mathrm{~kg}$ fertilizer nitrogen to

Table 1. Current nitrogen fertilizer recommendations for sugar beet and potatoes. $\mathrm{N}_{\text {rec }}=$ recommended rate; $N_{m 0-30}$, and $N_{m 0-60}$ are the amounts of soil mineral nitrogen in the layers $0-30$, and $0-60 \mathrm{~cm}$, respectively. $\mathrm{P}$ is set at 0.01 for sugar beet and 0.006 for potatoes. All amounts are expressed in $\mathrm{kg} \mathrm{N}$ per ha.

\begin{tabular}{llll}
\hline Crop & Soil type(s) & Organic manures & $\mathrm{N}_{\mathrm{rec}}$ \\
Sugar beet & $\begin{array}{l}\text { sand, loam, clay } \\
\text { sand, loam, clay }\end{array}$ & no, yes ${ }^{1}$ & $200-1.7 \mathrm{~N}_{\mathrm{m} 0-60}{ }^{2}$ \\
& green manures & $170-1.7 \mathrm{~N}_{\mathrm{m} 0-60}$ \\
Potatoes & sand & no, yes & $350-1.8 \mathrm{~N}_{\mathrm{m} 0-30}$ \\
& loam, clay & no, yes & $320-1.1 \mathrm{~N}_{\mathrm{m} 0-60}$ \\
\hline
\end{tabular}

${ }^{1}$ With the exception of green manures.

${ }^{2}$ When $\mathrm{N}_{\mathrm{m} 0-60}$ is $100-150, \mathrm{~N}_{\text {rec }}$ is fixed at 30 , when $\mathrm{N}_{\mathrm{m} 0-60}>150, \mathrm{~N}_{\mathrm{rec}}$ is 0 .

${ }^{3}$ When $\mathrm{N}_{\mathrm{m} 0-60}$ is 85-135, $\mathrm{N}_{\text {rec }}$ is fixed at 30 , when $\mathrm{N}_{\mathrm{m} 0-60}>135, \mathrm{~N}_{\text {rec }}$ is 0 . 
the price of 1 tonne produce was 0.01 for sugar beet and 0.006 for potato (Neeteson, 1989).

In the trials, soil mineral nitrogen was measured in various layers in early spring, and yield was measured at six or seven levels of fertilizer nitrogen. In 96 potato trials the amount of nitrogen in the tubers at harvest was measured. Details of the experimental design were given elsewhere (Neeteson \& Wadman, 1987; Neeteson \& Zwetsloot, 1989).

The yield associated with each recommendation was calculated from the response curve of each individual trial. For sugar beet modified exponential and for potatoes exponential response curves were fitted to the measured yields (Neeteson \& Zwetsloot, 1989). For sugar beet the yields were expressed as fresh beet yields with a sugar content of $16 \%$ (Neeteson \& Wadman, 1987), and for potatoes as fresh tuber yields. The nitrogen uptake by the potato tubers was found by interpolating between the measured amounts of nitrogen in the tubers at the fertilizer nitrogen levels actually applied. The recovery was calculated according to the difference method, i.e. the difference between nitrogen uptake with and without fertilizer nitrogen application, expressed as a percentage of the amount of fertilizer nitrogen applied. The recovery without fertilizer nitrogen, viz. an infinitely small amount of fertilizer nitrogen, was calculated from the tangent drawn to the nitrogen uptake response curve at zero- $\mathrm{N}$ application.

The effect of the value of the ratio $P$ on the economically optimum application rate of fertilizer nitrogen was determined from the average response curves of the 150 sugar beet and 98 potato trials, which were given in another paper (Neeteson, 1989). The optima and their $95 \%$ confidence intervals were calculated for various values of $P$ (ranging from 0.005 to 0.04 for sugar beet, and from 0.005 to 0.025 for potatoes) according to Neeteson \& Zwetsloot (1989).

\section{Results}

\section{Reduced rates of fertilizer nitrogen}

\section{Yields}

The average yields obtained with the current nitrogen fertilizer recommendations and with reduced rates of fertilizer nitrogen are shown in Table 2 . When the rates were reduced by $25 \%$, the average yields of both sugar beet and potatoes did not differ significantly from the yields obtained with the recommended rates. When $50 \%$ of the recommended rates was applied, average sugar beet and potato yields differed significantly $(P<0.05)$ from the yields obtained with the recommended rates, but the differences were relatively small: $2.5 \mathrm{tha}^{-1}$, i.e. $4 \%$.

The frequency distributions of the yield deficits with the reduced application rates of fertilizer nitrogen, i.e. the deviations of the yields from those obtained with the recommended rates of fertilizer nitrogen, were quite similar for sugar beet and potatoes (Fig. 1). With increasing reductions in application rates, the percentage of small deficits $(<1 \%)$ sharply decreased, whereas that of large yield deficits $(>5 \%)$ sharply increased. In about $6 \%$ of the sugar beet and potato trials large 


\section{J. J. NEETESON}

\section{cumulative}

frequency, $\%$
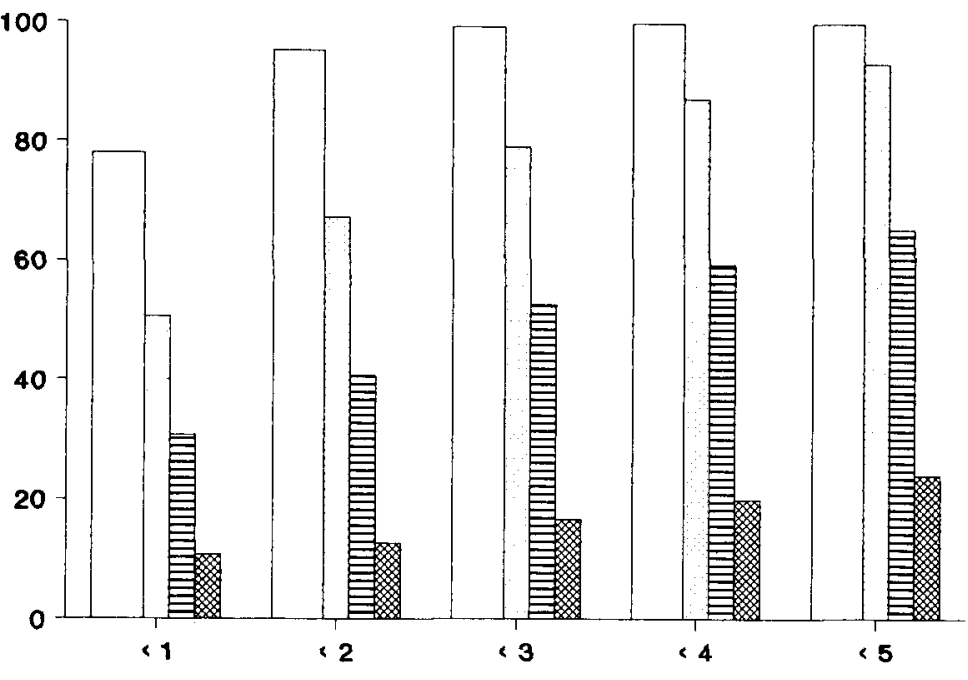

$\square$ 80\% $\square$ 75\%

b

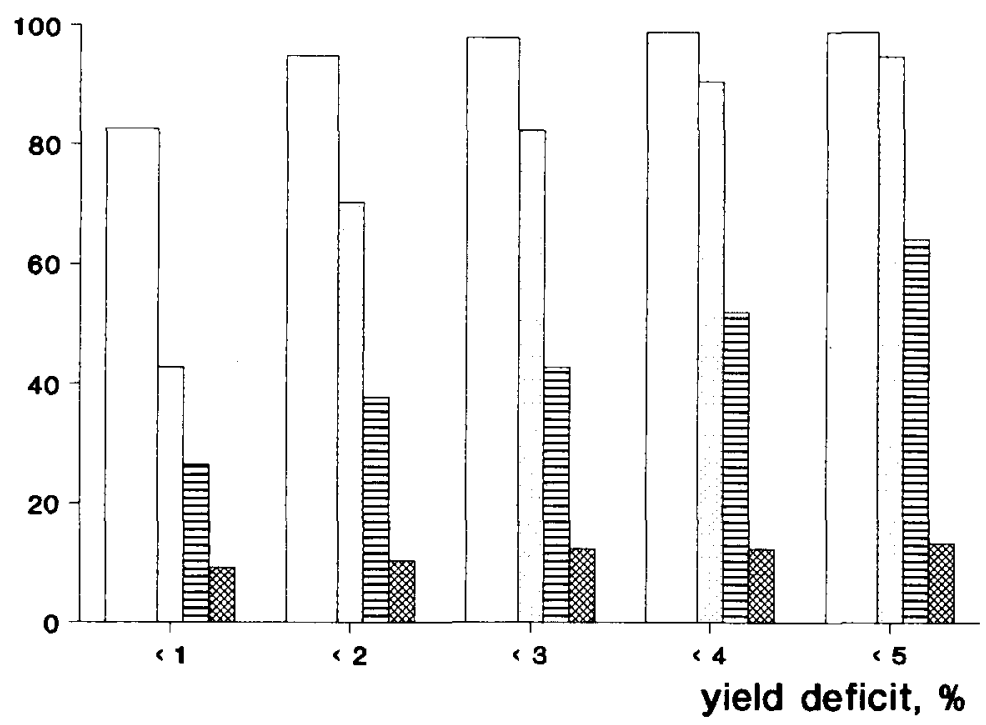

Fig. 1. Frequency distribution of the yield deficits for sugar beet (a) and potatoes (b) if $90,75,50$ or $0 \%$ of the fertilizer nitrogen recommended had been applied to 150 sugar beet and 98 potato trials. The yield deficits are expressed as a percentage of the yield obtained with the recommended application rate of fertilizer nitrogen in the trials. 
Table 2. Yields of sugar beet and potatoes for various reductions in the recommended fertilizer nitrogen rates. Average values of 150 sugar beet and 98 potato trials. Standard errors are given in parentheses.

\begin{tabular}{|c|c|c|c|c|}
\hline \multirow{2}{*}{$\begin{array}{l}\text { Fertilizer } \mathrm{N} \\
\text { applied } \\
\text { (\% of } \\
\text { recommended } \\
\text { rate) }\end{array}$} & \multicolumn{2}{|l|}{ Sugar beet } & \multicolumn{2}{|l|}{ Potatoes } \\
\hline & $\begin{array}{l}\text { yield } \\
\left(\mathrm{tha}^{-1}\right)\end{array}$ & $\begin{array}{l}\text { yield deficit } \\
\left(\mathrm{tha}^{-1}\right)\end{array}$ & $\begin{array}{l}\text { yield } \\
\left(\mathrm{t} \mathrm{ha}^{-1}\right)\end{array}$ & $\begin{array}{l}\text { yield deficit } \\
\left(\mathrm{tha}^{-1}\right)\end{array}$ \\
\hline 100 & $63.8(0.89)$ & 0 & $56.8(0.88)$ & 0 \\
\hline 90 & $63.5(0.90)$ & -0.3 & $56.5(0.88)$ & -0.3 \\
\hline 75 & $62.9(0.92)$ & -0.9 & $55.9(0.88)$ & -0.9 \\
\hline 50 & $61.2(0.96)$ & -2.6 & $54.4(0.91)$ & -2.4 \\
\hline 0 & $53.3(1.17)$ & -10.5 & $45.1(1.19)$ & -11.7 \\
\hline
\end{tabular}

yield deficits occurred when $75 \%$ of the nitrogen recommended was applied. When $50 \%$ of the nitrogen recommended was applied, this occurred in about $35 \%$ of the trials.

\section{Recovery of fertilizer nitrogen}

The recovery of fertilizer nitrogen by sugar beet is not dealt with here, because the nitrogen contents of the crop or parts of the crop were not measured.

The average fertilizer nitrogen recoveries by the potato tubers obtained with the reduced rates of fertilizer nitrogen are shown in Table 3. When $90 \%$ of the recommended rate was applied, the average recovery of fertilizer nitrogen did not significantly differ from the recovery at the recommended rate. When $75 \%$ and $50 \%$ of the recommended rates were applied, however, the average recovery increased significantly $(P<0.001)$ from 33 to 39 and $44 \%$, respectively.

In Fig. 2 the frequency distributions of the increases in fertilizer nitrogen recovery by the tubers obtained with the reduced rates of fertilizer nitrogen are shown, i.e. the difference between the recovery at the reduced rates and the recommended

Table 3. Fertilizer nitrogen recovery by the potato tubers for various reductions in the recommended fertilizer nitrogen rates. Average values of 96 trials. Standard errors are given in parentheses.

\begin{tabular}{lll}
\hline $\begin{array}{l}\text { Fertilizer } N \\
\text { applied } \\
\begin{array}{l}\% \text { of } \\
\text { recommended }\end{array}\end{array}$ & \multicolumn{2}{l}{ Fertilizer N recovery } \\
\cline { 2 - 2 } rate) & $(\%)$ & $\begin{array}{l}\text { difference from } \\
\text { recommended } \\
\text { rate }(\%)\end{array}$ \\
100 & & \\
90 & $33.2(1.14)$ & 0 \\
75 & $35.4(1.19)$ & 2.2 \\
50 & $38.7(1.25)$ & 5.5 \\
0 & $44.3(1.36)$ & 11.1 \\
\hline
\end{tabular}




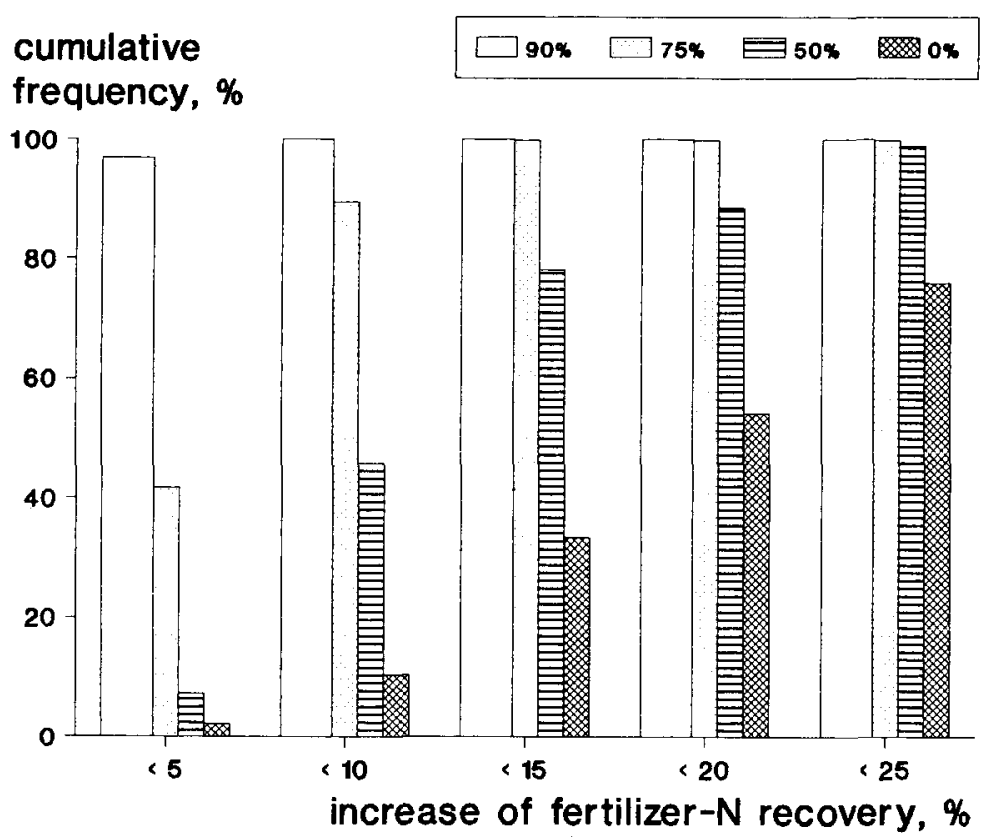

Fig. 2. Frequency distribution of the fertilizer nitrogen recovery by the potato tubers if $90,75,50$ or $0 \%$ of the fertilizer nitrogen recommended had been applied to 96 potato trials.



Fig. 3. Effect of the ratio $P$ of the cost of $1 \mathrm{~kg}$ fertilizer nitrogen to the price of 1 tonne produce on the average economically optimum application rate of fertilizer nitrogen for sugar beet and potatoes. $\mathrm{I}=$ $95 \%$ confidence interval for the optima. 
Table 4. Average effect of fertilizer nitrogen costs on gross financial yield of sugar beet and potatoes. The price of 1 tonne beets is fixed at Dfl. 100 and the price of 1 tonne potato tubers at Dfl. $200 . \mathrm{N}_{\mathrm{op}}=$ economically optimum application rate of fertilizer nitrogen, $\mathrm{Y}=$ yield.

\begin{tabular}{lllllr}
\hline Crop & $\begin{array}{l}\text { Cost of } 1 \mathrm{~kg} \\
\text { fertilizer } \mathrm{N} \\
\text { (Dfl.) }\end{array}$ & $\begin{array}{l}\mathrm{N}_{\mathrm{op}} \\
(\mathrm{kg} N \\
\text { per ha) }\end{array}$ & $\begin{array}{l}\mathrm{Y} \\
\left(\mathrm{t} \mathrm{ha}^{-1}\right)\end{array}$ & $\begin{array}{l}\text { Y-N } \\
(\mathrm{Dfl})\end{array}$ & $\begin{array}{l}\text { Yield deficit } \\
\text { (Dfl.) }\end{array}$ \\
Sugar beet & 1 & 134 & 63.72 & 6238 & 0 \\
& 2 & 126 & 63.67 & 6115 & 123 \\
& 3 & 118 & 63.58 & 6004 & 234 \\
& 4 & 111 & 63.45 & 5901 & 337 \\
Potatoes & 5 & 104 & 63.30 & 5810 & 428 \\
& & & & & \\
& 1 & 303 & 56.89 & 11075 & 0 \\
& 2 & 238 & 56.42 & 10808 & 267 \\
& 3 & 201 & 55.96 & 10589 & 486 \\
& 4 & 174 & 55.49 & 10402 & 673 \\
& 5 & 153 & 55.02 & 10239 & 836 \\
\hline
\end{tabular}

rate. When $90 \%$ of the recommended rate was applied, the increase in recovery was seldom higher than $5 \%$. At $75 \%$ of the rate recommended, the increase was between 0 and $15 \%$, whereas large increases $(>15 \%)$ occurred at $50 \%$ of the rate recommended or without fertilizer nitrogen application.

\section{Ratio between the cost of fertilizer nitrogen and the price of produce}

The relationship between the ratio $\mathrm{P}$ of the cost of fertilizer nitrogen and the price of produce, and the economically optimum application rate for fertilizer nitrogen of sugar beet and potatoes is shown in Fig. 3. With increasing values of $P$, for instance due to increasing costs of fertilizer nitrogen at constant prices of produce, the optima decreased. The effect of $P$ on the optimum was much smaller for sugar beet than for potatoes: a threefold increase in $P$ resulted in a decrease in the optimum of about $30 \mathrm{~kg} \mathrm{~N}$ per ha for sugar beet, but of about $100 \mathrm{~kg} \mathrm{~N}$ per ha for potatoes.

With the results presented in Fig. 3 and the yields obtained with the various optimum application rates of fertilizer nitrogen, the average effect of increasing costs of fertilizer nitrogen on the gross monetary yields of sugar beet and potatoes were calculated (Table 4). In the calculations it was assumed that all costs other than nitrogen fertilizer costs do not change with decreasing application rates of fertilizer nitrogen. The results of Table 4 clearly show that increasing nitrogen fertilizer costs have a strong impact on farm income.

\section{Discussion}

\section{Reduced rates of fertilizer nitrogen}

When the application rates of fertilizer nitrogen recommended for sugar beet and 

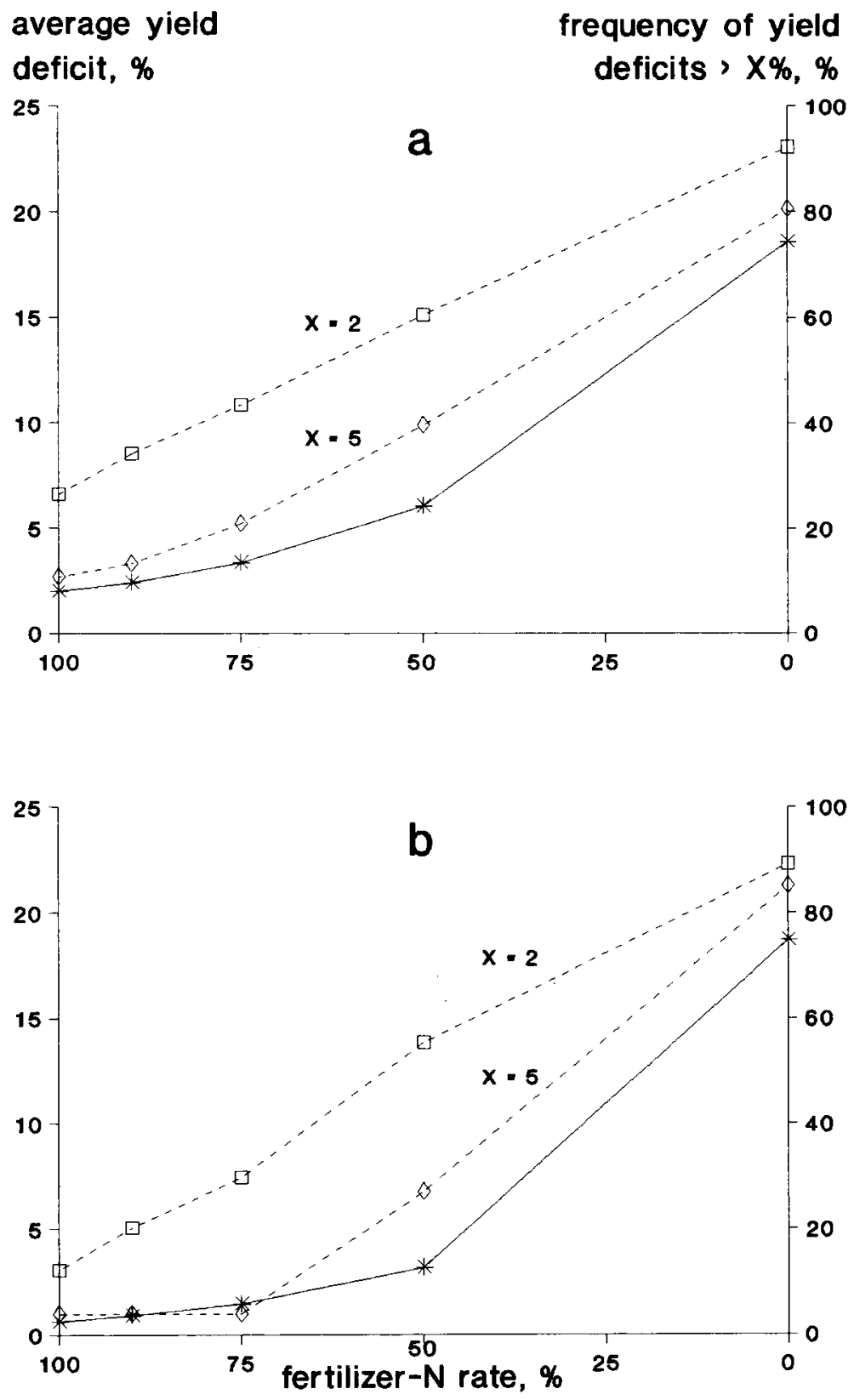

Fig. 4. Relationship between reduced fertilizer nitrogen rates, and average yield deficits (solid lines) and the frequency of occurrence of yield deficits (broken lines) in sugar beet (a) and potatoes (b). The relationships are based on 150 sugar beet and 98 potato trials. The yield deficits are expressed as a percentage of the yield obtained with the measured optimum application rate of fertilizer nitrogen in the trials. 
potatoes were reduced by $25 \%$, yields were obtained which on average did not differ from those obtained with the recommended rates (Table 2), but the chance of getting serious yield deficits $(>5 \%)$ increased by about $5 \%$ (Fig. 2). Apparently, the current nitrogen fertilizer recommendations for sugar beet and potatoes can be reduced without substantial loss of yield. How far the recommendations can be reduced can be derived from the relationships between the reduction in fertilizer rate, and the average yield deficit and the frequency of occurrence of yield deficits (Fig. 4). In Fig. 4 the yield deficits are not expressed as a percentage of the yield obtained with the current recommendation as was done in Table 2 and Fig. 1, but as a percentage of the yield obtained with the measured optimum application rate of fertilizer nitrogen in the trials. When it is assumed that an average yield deficit of $2 \%$ is acceptable, the current recommendation for sugar beet cannot be lowered, because the average yield deficit with the recommendation already amounted to $2 \%$ (Fig. $4 a$ ), but the recommendation for potatoes can be reduced by $32 \%$ (Fig. $4 \mathrm{~b}$ ). The chance of serious yield deficits is then about $11 \%$ (Fig. 4b). When it is assumed, however, that the chance of serious yield depressions is not allowed to exceed $5 \%$, the current recommendation for sugar beet cannot be lowered (Fig. 4a), but for potatoes it can be reduced by $27 \%$ (Fig. 4b). In that case the average yield deficit will be $1.7 \%$ (Fig. $4 \mathrm{~b}$ ), and the recovery of fertilizer nitrogen by the potato tubers will be about $40 \%$ (Table 3 ).

From the farmer's point of view no measures should be taken which reduce yields of sugar beet and potatoes, because these crops have a strong impact on the income of Dutch farmers. When sugar beet and potatoes are grown in a four-year rotation with winter wheat and spring barley, sugar beet contribute up to $30 \%$ and potatoes up to $35 \%$ of the total net monetary yield; these figures are about 35 and $45 \%$ when sugar beet and potatoes are grown in a three-year rotation with winter wheat (Anon., 1988).

It should be noted here that the effects of reduced fertilizer nitrogen rates shown in this paper are short-term effects. Because the amount of crop residues remaining in the soil will decrease with decreasing inputs of fertilizer nitrogen, resulting in decreasing contributions of nitrogen mineralized from those residues, it is to be expected that the long-term effects of reduced nitrogen applications will be larger.

\section{Ratio between the cost of fertilizer nitrogen and the price of produce}

The data shown in Fig. 3 can be used to adjust nitrogen fertilizer recommendations for sugar beet and potatoes to changing costs of fertilizer nitrogen and/or changing prices of produce. A change in the ratio $\mathrm{P}$ had a much smaller effect on the economically optimum application rate for sugar beet than on that for potatoes. This is due to the relatively steep course of the response curve of sugar beet (Neeteson, 1989). As the shapes of response curves of cereals (Dilz, 1981; Sylvester-Bradley et al., 1983) are generally similar to that of sugar beet, it is to be expected that a change in the value of $\mathrm{P}$ will also have relatively little effect on the economically optimum application rate of fertilizer nitrogen for cereals.

If a levy would be imposed on nitrogen fertilizer to restrict the use of nitrogen fer- 
tilizers in order to protect the environment, its effects on the use of nitrogen fertilizers for sugar beet would be small. A fivefold increase in the costs of fertilizer nitrogen would decrease the economically optimum application rate of fertilizer nitrogen by only about $20 \%$ (Table 4 ). For potatoes the effects would be much larger: a fivefold increase in fertilizer nitrogen costs would halve the optimum application rate (Table 4). The effects on farm income, however, would be considerable (Table 4). Imposing a levy on fertilizers is therefore only justified if the decrease in fertilizer use would clearly reduce the environmental effects of fertilizer application. As long as fertilizer nitrogen is applied according to the recommendations, it is doubtful if reduced applications to sugar beet would affect nitrate leaching. Due to the high nitrogen uptake efficiency of the crop it has been found that the amount of soil mineral nitrogen at harvest is not affected by the amount of fertilizer nitrogen applied (Lindén, 1987; Neeteson \& Ehlert, 1989). Thus, assuming that the sugar-beet tops are removed from the field, leaching of fertilizer nitrogen in autumn and winter is not likely to occur. Reduced applications to potatoes perhaps lower the amount of nitrate leached, because fertilizer nitrogen application may increase soil mineral nitrogen at harvest, although experimental evidence is scarce (Prins et al., 1988).

\section{References}

Anon., 1986. Fertilizer recommendations for arable crops (in Dutch). Consulentschap voor bodem-, water- en bemestingszaken in de akkerbouw en tuinbouw, Wageningen, $28 \mathrm{pp}$.

Anon., 1988. Quantitative information, 1988-1989 (in Dutch). Consulentschap en Proefstation voor de akkerbouw en de groenteteelt in de volle grond, Lelystad, $184 \mathrm{pp}$.

Dilz, K., 1981. The nitrogen fertilization of spring barley. Plant and Soil 61: 269-276.

Lindén, B., 1987. Reasons for variations in optimum demand of fertilizer nitrogen in sugar beet production. In: N. E. Nielsen (Ed.), Proceedings 3rd Meeting NW European study group for the assessment of nitrogen fertilizer requirement, p. 72-87. The Royal Veterinary and Agricultural University, Copenhagen.

Neeteson, J. J., 1989. Evaluation of the performance of three advisory methods for nitrogen fertilization of sugar beet and potatoes. Netherlands Journal of Agricultural Science 37: 143-155.

Neeteson, J. J. \& P. A. I. Ehlert, 1989. Environmental aspects of applying inorganic fertilizers to sugar beet. Proceedings 52nd Winter Congress. International Institute for Sugar Beet Research, Brussels (in press).

Neeteson, J. J. \& W. P. Wadman, 1987. Assessment of economically optimum application rates of fertilizer $\mathrm{N}$ on the basis of response curves. Fertilizer Research 12: 37-52.

Neeteson, J. J. \& H. J. C. Zwetsloot, 1989. An analysis of the response of sugar beet and potatoes to fertilizer nitrogen and soil mineral nitrogen. Netherlands Journal of Agricultural Science 37: 129-141.

Prins, W. H., K. Dilz \& J. J. Neeteson, 1988. Current recommendations for nitrogen fertilisation within the EEC in relation to nitrate leaching. Proceedings 276. The Fertiliser Society, London, $27 \mathrm{pp}$.

Sylvester-Bradley, R., P. M. R. Dampney \& A. W. A. Murray, 1983. The response of winter wheat to nitrogen. In: The nitrogen requirement of cereals. Reference Book 385, p. 151-174. MAFF/ADAS, London.

Williams, A. J., 1988. EEC management of agricultural production and its implications for the fertiliser industry. Proceedings 275 . The Fertiliser Society, London, $28 \mathrm{pp}$. 